\title{
Effect of Cooling and Shot Peening on Residual Stresses and Fatigue Performance of Milled Inconel 718
}

\author{
Zhe Chen ${ }^{1, a^{*}}$, Ru Lin Peng ${ }^{1, ~ b}$, Johan Moverare ${ }^{1, c}$, Olle Widman ${ }^{2, d}$, \\ David Gustafsson ${ }^{3, e}$, Sten Johansson ${ }^{1, f}$ \\ ${ }^{1}$ Division of Engineering Materials, Linköping University, 58183 Linköping, Sweden \\ ${ }^{2}$ Ytstruktur Arboga AB, 73222 Arboga, Sweden \\ ${ }^{3}$ Siemens Industrial Turbomachinery AB, 61283 Finspång, Sweden \\ azhe.chen@liu.se, bru.peng@liu.se, cjohan.moverare@liu.se, ${ }^{d}$ olle.widman@ytstrukturarboga.se, \\ edavid.gustafsson@siemens.com, sten.johansson@liu.se
}

Keywords: Residual Stresses, Surface Integrity, Milling, Shot Peening, Superalloys, Fatigue

\begin{abstract}
The present study highlights the effect of cooling and post-machining surface treatment of shot peening on the residual stresses and corresponding fatigue life of milled superalloy Inconel 718. It was found that tensile residual stresses were created on the milled surface, regardless of the use of coolant, however, the wet milling operation led to a lower surface tension and a reduced thickness of the tensile layer. The shot peening performed on the dry-milled specimens completely annihilated the surface tensile residual tresses and introduced a high level of surface compression. A comparable fatigue life for the wet-milled specimens was obtained as compared with the specimens prepared by dry milling. This is very likely attributed to that the milling-induced surface damage with respect to cracked nonmetallic inclusions is the predominant cause of the fatigue failure. The presence of the compressive layer induced by shot peening resulted in a significant increase of the fatigue life and strength, while the extent to which the lifetime was prolonged was decreased as the applied load was increased.
\end{abstract}

\section{Introduction}

Fatigue is one of the main causes of failure to various structures in turbine engines. The fatigue life of a component strongly depends on its surface condition produced by machining since in most cases fatigue crack initiation starts on free surfaces. Residual stress is one of the most relevant practical parameters to assess the surface quality of a machined surface; it is superimposed on the applied cyclic loads, altering the driving force for crack initiation and propagation during fatigue. Generally, tensile residual stresses are perceived to be detrimental to the fatigue performance, whereas compressive residual stresses have a beneficial effect. The formation of residual stresses in machining processes is essentially dominated by the plastic deformation in subsurface of the workpiece material together with the thermal impact at surface [1]. The thermally-induced residual stresses are usually in tension, thus sufficient cooling could effectively reduce the surface tension on a machined surface by lowering the cutting temperature, or even introduce compressive residual stresses [2].

On the other hand, mechanical surface treatments, such as shot peening, are nowadays widely used on machined components by which compressive residual stresses are induced as it produces a workhardened layer and misfit strains between the bulk and surface material. An enhanced fatigue life and strength by shot peening have been found for a variety of engineering materials [3-5].

Inconel 718 is a polycrystalline nickel-based superalloy and has wide applications in aerospace and power generation industries because of its superior mechanical properties and good resistance to oxidation/corrosion environments. A great number of studies have been conducted to improve the surface integrity of machined Inconel 718 by approaches with process optimization or post-machining surface treatments (like shot peening) [6]. However, further investigations on the effect of changes in 
surface integrity on the fatigue properties of the components are somewhat limited although it has a great practical importance for the assessment of the component life and also the knowledge obtained can be used backwards to guide the surface integrity modification. The purpose of the current study is to characterize the residual stresses generated on milled Inconel 718 as influenced by the use of coolant and a subsequent shot-peening treatment. Meanwhile, the fatigue performance of the specimens corresponding to the different surface conditions has also been studied in a four-point bending mode.

\section{Experimental work}

The material used in this study was taken from a disc forging of Inconel 718 with chemical composition given in Table 1 . The forging was solution annealed at $970{ }^{\circ} \mathrm{C}$ followed by air cooling to room temperature, and then a two-stage ageing was performed first at $720{ }^{\circ} \mathrm{C}$ for $8 \mathrm{~h}$, further at $620{ }^{\circ} \mathrm{C}$ for another $8 \mathrm{~h}$, and finally air cooled to room temperature.

Table 1. Chemical composition [wt\%] of the Inconel 718 disc forging.

\begin{tabular}{lllllllll}
\hline & $\mathrm{Fe}$ & $\mathrm{Ni}$ & $\mathrm{Cr}$ & $\mathrm{Mo}$ & $\mathrm{Nb}$ & $\mathrm{Ti}$ & $\mathrm{Al}$ & $\mathrm{C}$ \\
\hline Min. (\%) & Bal. & 50 & 17 & 2.8 & 4.75 & 0.65 & 0.2 & \\
Max. (\%) & & 55 & 21 & 3.3 & 5.5 & 1.15 & 0.8 & 0.08 \\
\hline
\end{tabular}

Fatigue test bars with a dimension of $10 \times 10 \times 80 \mathrm{~mm}^{3}$ were pre-manufactured from the heat-treated forging by wire electric discharge machining. The surface to be loaded in tension during fatigue was then machined by face milling using a $20 \mathrm{~mm}$ diameter cutter with two uncoated cemented carbide inserts. The cutting speed was fixed at $30 \mathrm{~m} / \mathrm{min}$ (corresponding spindle speed was $382 \mathrm{rpm}$ ) and the depth of cut was $0.5 \mathrm{~mm}$. The feed direction was along the longitudinal direction of the bar with a feed rate of $76 \mathrm{~mm} / \mathrm{min}$. Chamfers on the tensile side were introduced in order to avoid corner crack initiation. Three groups of specimens were prepared; the specimens of the first two groups were dry milled and milled under coolant respectively, while for the last group, the surface that has been machined by dry milling was subsequently shot peened using spherical S170 H cast steel shots with 150 to $200 \%$ surface coverage, while the shot-peening intensity was varied from 0.2 to $0.3 \mathrm{mmA}$.

The microstructure beneath the dry-milled, wet-milled and shot-peened surface was characterized on polished cross-sections prior to fatigue testing using a scanning electron microscope (SEM) together with electron channeling contrast imaging (ECCI). In addition, the In-depth residual stresses created by milling and shot peening were measured by using X-ray diffraction, combined with layer removal by electrolytical polishing. $\mathrm{Cr}-\mathrm{K} \alpha$ radiation was chosen, giving a diffraction peak at $2 \theta \sim 128^{\circ}$ for the $\{220\}$ family of lattice planes of the nickel-based matrix. Peaks were measured at nine $\psi$-angles between $\psi= \pm$ $55^{\circ}$, and residual stresses were calculated based on the " $\sin ^{2} \psi$ " method [7] with an X-ray elastic constant of $4.65 \times 10^{-6} \mathrm{MPa}^{-1}$. Deviation in the measured residual stresses due to the layer removal were corrected in the case of a flat plate.

All fatigue tests were conducted at room temperature under load control using a sinusoidal waveform at a load ratio of 0.1 and a frequency of $20 \mathrm{~Hz}$. The distance between the two loading and two supporting rollers was $12 \mathrm{~mm}$ and $60 \mathrm{~mm}$, respectively. For each group of the three, four specimens were tested at different peak loads in the range of $8 \mathrm{kN}$ to $16 \mathrm{kN}$. The corresponding peak stress at the surface, calculated assuming pure elastic loading, were approximately $600 \mathrm{MPa}$ to $1200 \mathrm{MPa}$. The yield strength of the Inconel 718 forging at room temperature, on the other hand, is slightly above $1000 \mathrm{MPa}$. All specimens were fatigued until rupture and the specimen deflection at the maximum/minimum load versus the number of cycles was recorded. A line was fitted to the initial linear part of the deflection range-number of cycles curve and extrapolated to the larger cycle region. The number of cycles corresponding to $1 \%$ increase of the deflection range from the fitted line was then defined as the fatigue life in the present study. Accordingly, the lifetime of the specimens is largely dominated by the fatigue cycles spent on crack initiation. The failed specimens were examined under SEM in order to identify the preferential sites where fatigue cracks may initiate. 


\section{Results and discussions}

Fig. 1(a) and (b) shows the in-depth residual stresses induced by dry milling and wet milling. Stress components in two in-plane directions, i.e. transverse direction (TD) and longitudinal direction (LD) (corresponding to the cutting direction and feed direction), were measured. In general, tensile residual stresses were created on the milled surface, regardless of the application of coolant, but it is clear that the wet milling operation led to a lower surface tension and a reduced thickness of the tensile layer. As the depth increases, the residual stresses gradually shift to compression until stabilizing at $\sim 0 \mathrm{MPa}$.

(a)

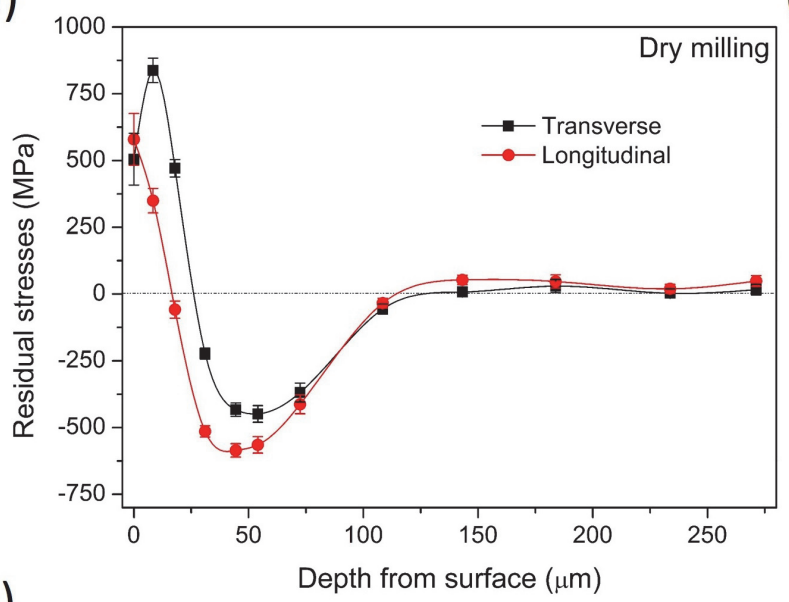

(c)

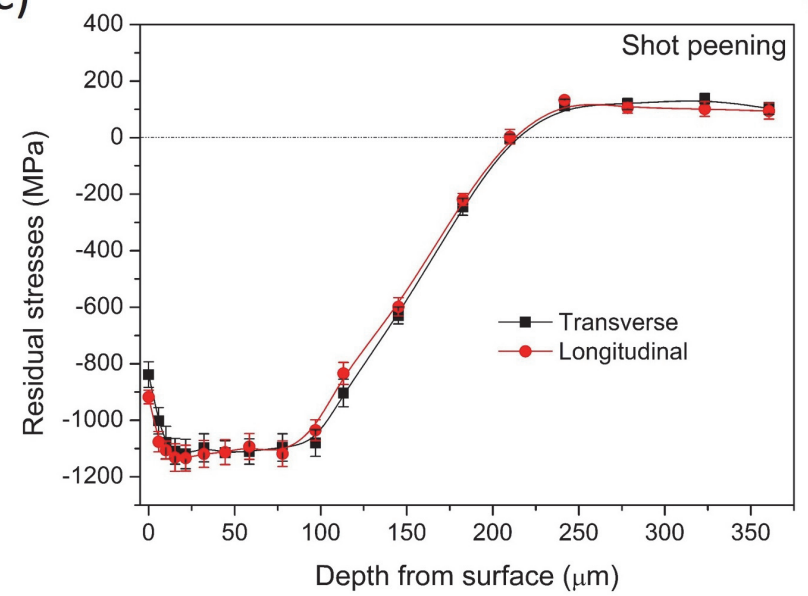

(b)

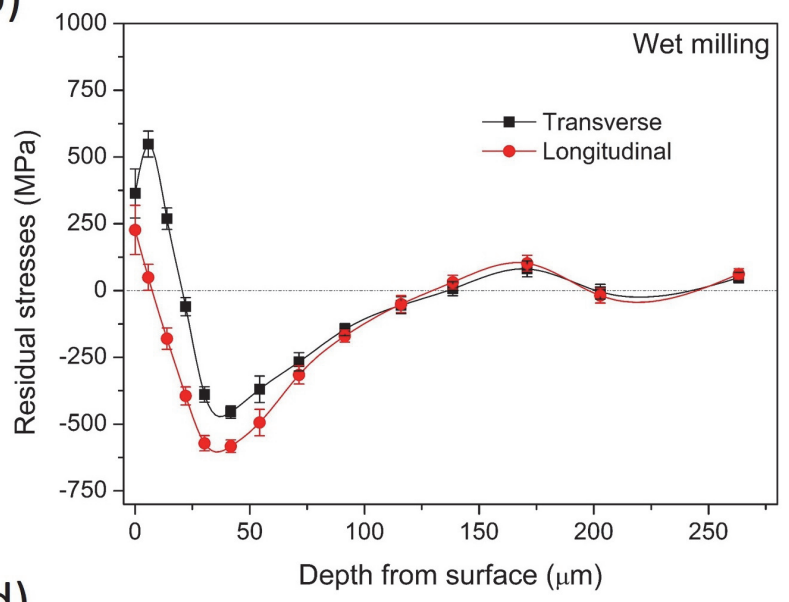

(d)

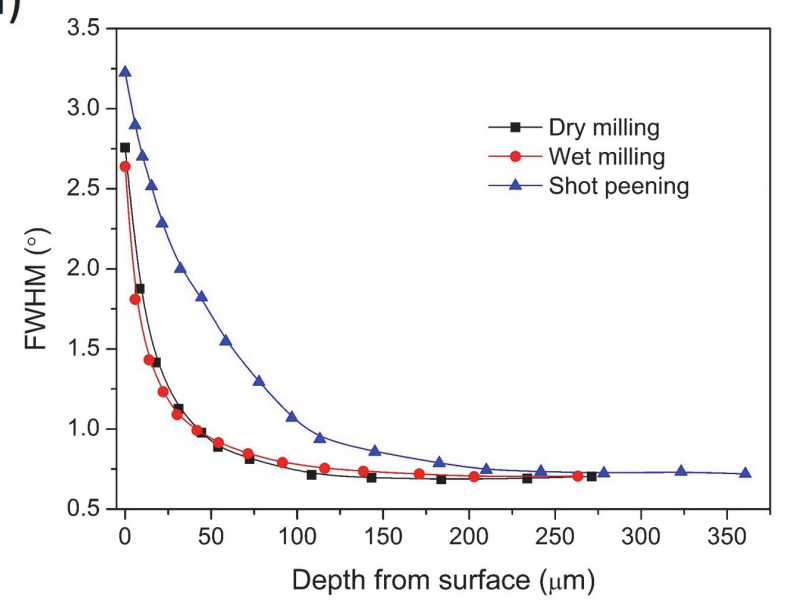

Figure 1. In-depth residual stresses generated by (a) dry milling, (b) wet milling, and (c) shot peening; (d) A comparison of the full width at half maximum intensity (FWHM) obtained from the measured diffraction peaks.

The post-milling surface treatment by shot peening annihilated the high tension on the dry-milled surface and introduced a surface plateau, extending to a depth of $100 \mu \mathrm{m}$, with great compressive residual stresses in both TD and LD, see Fig. 1(c). The high level of surface compression was created as a consequence of the mechanically-induced plastic deformation during shot peening. This can be seen from the dramatically increased broadening of the diffraction peaks, i.e. full width at half maximum intensity (FWHM), measured in the shot-peened surface layer, see Fig. 1(d). The formation of the tensile residual stresses on the milled surface is most likely to be of thermal origin associated with the great heat generation during machining [1]. From Fig. 1(d), one can see that the wet-milled surface underwent less plastic deformation compared with that in the case of dry milling. A very likely explanation is that the coolant could contribute to lowering the friction and dissipating the generated heat, leading to a relatively low cutting temperature. As an effect of the reduced cutting temperature, the thermally-induced residual stresses became less in tension on the surface produced by wet milling. The 
reduced thermal impact during wet milling can be further supported by the microstructural characterization beneath the milled surfaces. Instead of a continuous thick white layer, approximately 4 to $5 \mu \mathrm{m}$, as observed on the dry-milled surface (Fig. 2(a)), the surface white layer appeared discontinuously with a thickness less than $1 \mu \mathrm{m}$ on the wet-milled surface (Fig. 2(b)). As suggested by Bushlya et al. [8], the development of white layers takes place in machining of Inconel 718 normally when the cutting temperature is increased, e.g. at high cutting speeds, cutting with worn tools or in dry machining operations. The shot-peened surface compared with the dry-milled surface showed significantly increased plastic deformation in microstructure, see Fig. 2(c), which is consistent with the greatly higher FWHM measured in the shot-peened layer.
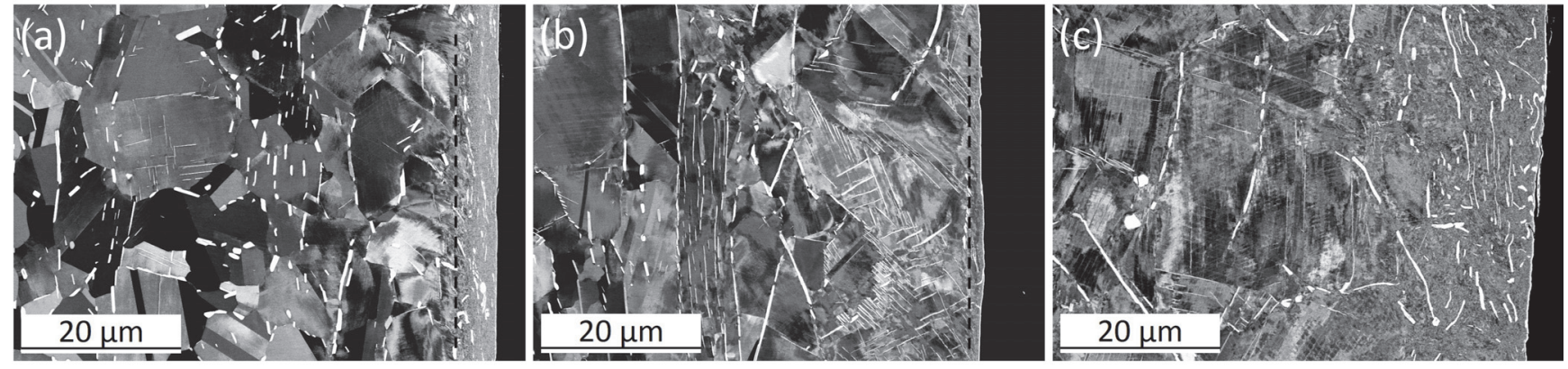

Figure 2. Electron channeling contrast imaging (ECCI) micrographs showing the microstructure beneath (a) the dry-milled surface, (b) the wet-milled surface, and (c) the shot-peened surface. In (a) and (b), dash lines are drawn to compare the thickness of the superficial white layer formed in dry and wet milling.

A comparison of the fatigue performance as influenced by the use of coolant and post-machining surface treatment of shot peening is presented in Fig. 3. Although relatively low surface residual stresses were obtained by wet milling, the fatigue life was observed to be comparable with that for the specimens prepared by dry milling. However, in the high-cycle regime with a lower applied load, it showed a slight increase in fatigue resistance for the wet-milled condition which is very likely due to a stronger effect of residual stresses. The shot peening, on the other hand, led to a great increase of the fatigue life, particularly in the high-cycle regime; the enhancement could be up to roughly two orders of magnitude compared with the lifetime of the dry-milled specimens.

Fracture surface examinations can offer insights into the fatigue failure mechanism of the specimens with different surface conditions. Shown in Fig. 4 is an example of the typical fracture appearance observed on the fatigued specimens with either a dry-milled or wet-milled surface. It can be clearly seen that multiple cracks were initiated at the milled surface during fatigue loading and the coalescence of the cracks led to a macroscopic fluctuant fracture surface. Close examinations further revealed that the initiation of fatigue cracks took place primarily associated with the cracking of surface non-metallic inclusions (Nb-rich carbides and/or Ti-rich nitrides). Previous studies by the authors [9] have shown that the giant plastic work during machining of Inconel 718 could cause cracking of non-metallic inclusions on the machined surface. In this study, substantial cracked carbides as well as a few cracked nitrides (due to the much lower amount of nitrides in the alloy) were also observed after the milling operations. These pre-existing surface defects provide multiple sites where fatigue cracks preferably initiate, or could even start to grow without an incubation of nucleation. Based on such predominance of the failure mechanism, the comparable fatigue life of the specimens prepared by dry and wet milling is very likely attributed to the similar damage on the milled surfaces with respect to the non-metallic inclusion cracking. The effect of residual stresses in this case appears to be less significant.

In the case of the shot-peened specimens, the surface compression was deep and strong enough to shift the crack initiation sites to subsurface regions corresponding to the depth of the compressive layer, see Fig. 5. The surface microstructure of the shot-peened specimens still consists of a large amount of cracked inclusions, however, the development of fatigue cracks from these flaws was retarded due to the 
presence of the great compressive residual stresses. As a result, an enhanced fatigue life and strength were obtained, as shown in Fig. 3. The beneficial effect of compressive residual stresses in terms of retarding surface cracking during fatigue and increasing the resistance of the component to fatigue failures is well consistent with the previous findings in shot peening of other metallic materials $[3,4]$. The extent to which the lifetime was prolonged was decreased as the applied load was increased due to the residual stress relaxation in low cycle fatigue resulting from significant cycling strains [10].

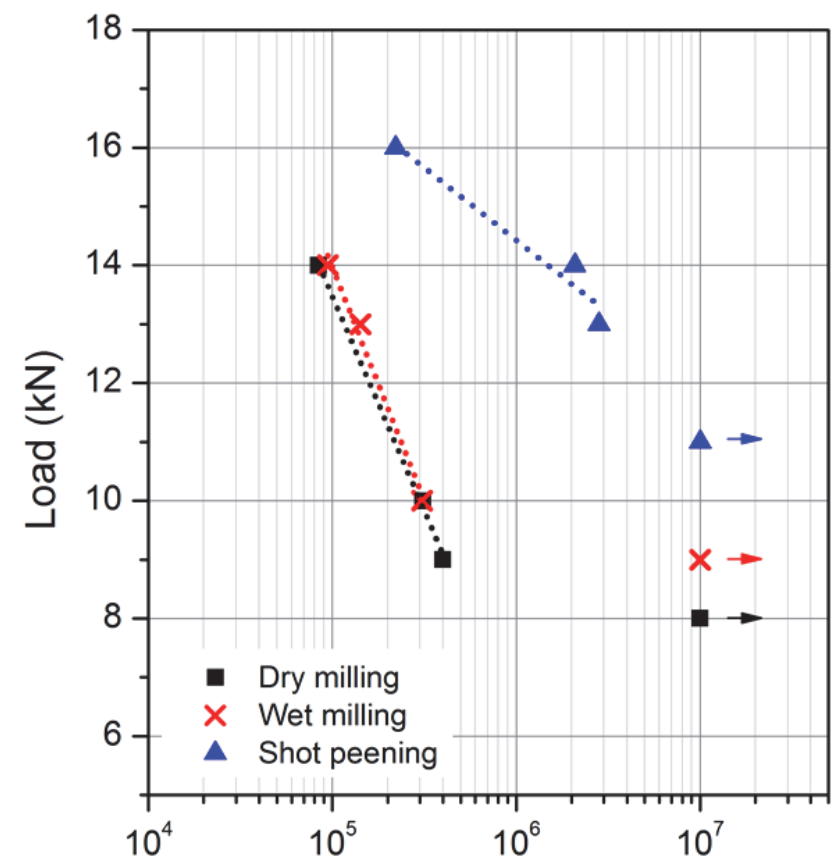

Cycles to failure
Figure 3. A comparison of the obtained fatigue life as influenced by the use of coolant as well as the post-machining surface treatment of shot peening.

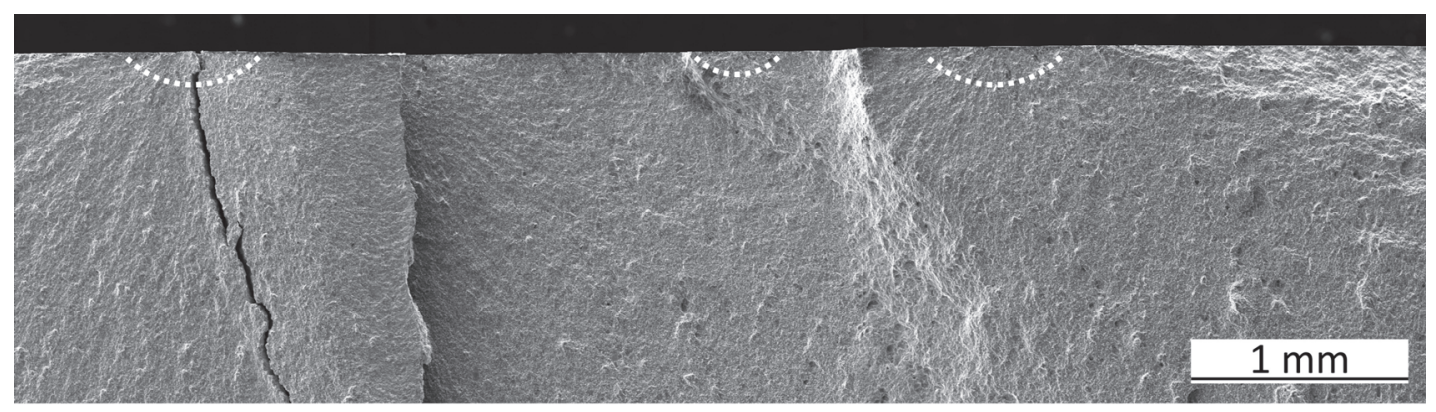

Figure 4. Typical fracture appearance after the fatigue of the milled specimens regardless of the use of coolant where multiple crack initiation sites at the milled surface were observed; some of them are located by dash lines.

\section{Conclusions}

The present work investigated the residual stresses generated on milled Inconel 718 as influenced by the use of coolant in machining or by post-machining surface treatment with shot peening. The corresponding fatigue performance of the specimens was also investigated. The results showed that the wet milling led to reduced tensile residual stresses on the machined surface compared with that in the case of dry milling. However, a comparable fatigue life was obtained for the specimens milled with or without the use of the coolant. This is very likely due to that for both conditions the milling-induced surface damage with respect to cracked non-metallic inclusions dominated the crack initiation during fatigue. The shot-peening treatment annihilated the surface tension induced by milling and introduced high compressive residual stresses. The presence of the compressive layer retards surface cracking from the pre-existing cracked carbides and/or nitrides and shifts the crack initiation sites to sub-surface 
regions, leading to a significant increase of the fatigue life and strength for the shot-peened specimens. The extent to which the lifetime was prolonged was reduced as the applied load was increased.

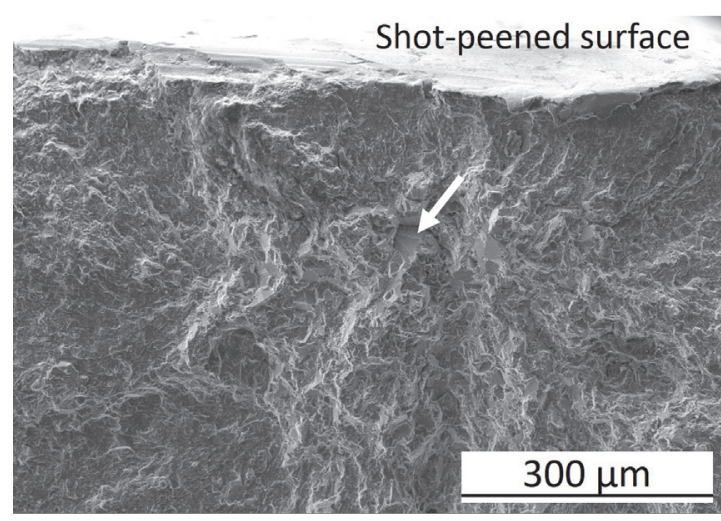

Figure 5. Fatigue fracture surface of a shotpeened specimen where it shows a transition of the crack initiation site from surface to subsurface regions (pointed by the arrow) compared with the observation in Fig. 4.

\section{Acknowledgements}

Faculty grant SFO-MAT-LiU\#2009-00971 at Linköping University, Ytstruktur Arboga AB and Siemens Industrial Turbomachinery $\mathrm{AB}$ are acknowledged for their valuable supports in this study.

\section{References}

[1] K. Jacobus, R. DeVor, S. Kapoor, Machining-induced residual stress: experimentation and modeling, J. Manuf. Sci. Eng. 122 (2000) 20-31.

http://dx.doi.org/10.1115/1.538906

[2] F. Pusavec, H. Hamdi, J. Kopac, I. Jawahir, Surface integrity in cryogenic machining of nickel based alloy-Inconel 718, J. Mater. Process. Technol. 211 (2011) 773-783.

http://dx.doi.org/10.1016/j.jmatprotec.2010.12.013

[3] J. Lindemann, C. Buque, F. Appel, Effect of shot peening on fatigue performance of a lamellar titanium aluminide alloy, Acta Mater. 54 (2006) 1155-1164.

http://dx.doi.org/10.1016/j.actamat.2005.10.043

[4] L. Wagner, Mechanical surface treatments on titanium, aluminum and magnesium alloys, Mater. Sci. Eng. A 263 (1999) 210-216.

http://dx.doi.org/10.1016/S0921-5093(98)01168-X

[5] Y. Choi, A study on the effects of machining-induced residual stress on rolling contact fatigue, Int. J. Fatigue 31 (2009) 1517-1523.

http://dx.doi.org/10.1016/j.ijfatigue.2009.05.001

[6] A. Thakur, S. Gangopadhyay, State-of-the-art in surface integrity in machining of nickel-based super alloys, Int. J. Mach. Tools Manuf. 100 (2016) 25-54.

http://dx.doi.org/10.1016/j.ijmachtools.2015.10.001

[7] I.C. Noyan, J.B. Cohen, Residual stress-measurement by diffraction and interpretation, (1986).

[8] V. Bushlya, J. Zhou, F. Lenrick, P. Avdovic, J. Ståhl, Characterization of white layer generated when turning aged Inconel 718, Procedia Eng. 19 (2011) 60-66.

http://dx.doi.org/10.1016/j.proeng.2011.11.080

[9] Z. Chen, R.L. Peng, J. Moverare, P. Avdovic, J. Zhou, S. Johansson, Surface integrity and structural stability of broached Inconel 718 at high temperatures, Metall. Mater. Trans. A 47 (2016) 3664-3676.

http://dx.doi.org/10.1007/s11661-016-3515-6

[10] R. McClung, A literature survey on the stability and significance of residual stresses during fatigue, Fatigue Fract. Eng. Mater. Struct. 30 (2007) 173-205.

http://dx.doi.org/10.1111/j.1460-2695.2007.01102.x 